\title{
Genetic Diversity in Citrus
}

\author{
Aydin Uzun ${ }^{1 *}$ and Turgut Yesiloglu² \\ ${ }^{1}$ Erciyes University Department of Horticulture, Kayseri \\ ${ }^{2}$ Cukurova University Department of Horticulture, Adana \\ Turkey
}

\section{Introduction}

Citrus is the most produced fruit in the world with over the 116 million tons of production (FAO, 2009). Besides, citrus is an extremely important crop on a world-wide basis, and is grown wherever the climate is suitable. It is widely grown in most areas with suitable climates tropical, subtropical, and borderline subtropical/temperate (Kahn et al., 2001).

The genus Citrus L. belongs to the subtribe Citrineae, the tribe Citreae within the subfamily Aurantioideae of the Rutaceae family (Webber, 1967). The Aurantioideae is one of seven subfamilies of Rutaceae which consists of two tribes and 33 genera. Each of tribes Clauseneae and Citreae is composed of three subtribes. Clauseneae includes Micromelinae, Clauseninae and Merrillinae, and Citreae has Triphasiinae, Citrinae and Balsamocitrinae. The Citrinae is distinct from all the other subtribes in the subfamily by having pulp vesicles in the fruit. This subtribe contains three groups; primitive citrus fruit, near citrus fruit, and true citrus fruit trees. True citrus fruits have six genera: Clymenia, Eremocitrus, Microcitrus, Poncirus, Fortunella and Citrus (Swingle \& Reece, 1967).

Most of genus including Citrus belongs to subfamily Aurantioideae originated from Monsoon regions and expand from West Pakistan to China, India islands, Northwest Australia, New Guinea. In this subfamily, four of 33 genus (Afraegle, Aeglopsis, Balsamocitrus and Citropsis) native to tropical Africa an one genus (Clausena) native to Monsoon and tropical Africa. Besides, Microcitrus and Eremocitrus originated from Australia (Ulubelde, 1985).

Spreading citrus to other parts of the world goes back to B.C. The first species reached to Europe was citron. This species brought to Iran by Persian and then spreaded to Europe. Sour orange and lemon were brought to Europe by the Romans through trades in first and second century A.D. A mosaic tile floor found in a Roman villa at Carthage, probably of the second century A.D., shows recognizable branches of citron and fruit-bearing lemon trees. Although there is still no consensus on the definitive homeland of lemon, this species have been described and it's name pronounced as 'li-mung' in resources books writtened by Fan Ch'eng-Ta ve Chou K'ü-Fei in 1175 and 1178 A.D. By 1150 A.D. the Arabs had brought citron, sour orange, lemon and pummelo into North Africa and Spain.

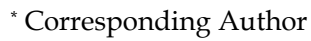


In the written sources, sweet orange did not seem to had been widely cultivated until toward the middle of the fifteenth century. Portuguese succeeded in rounding Southern Africa soon brought better sweet oranges from India or Far East to Europe. By the beginning of the sixteenth century, there was abundant evidence showing that it had become well established and becomecommercially important in southern Europe. The mandarin, native to China was brought to Europe in 1805. Firstly it came to England and then spread to Malta, Scily and Italy. The pummelo or shaddock in its journey to Europe apparently followed about the same path as the sweet and sour oranges. It is notified that the seed of shaddock was first brought to Barbados by Captain Shaddock. The grapefruit, which probably originated as a mutation or sport from the shaddock, was first described under the name 'forbidden fruit' by Griffith Hughes in 1750 from Barbados. From Europe citrus spread to the New World firstly by Columbus in 1493 and then continued (Webber, 1967; Scora, 1975).

Citrus taxonomy and phylogeny are very complicated, controversial and confusing, mainly due to sexual compatibility between Citrus and related genera, the high frequency of bud mutations and the long history of cultivation and wide dispersion (Nicolosi et al., 2000). In addition, the level of difference in relation to species status in Citrus is uncertain. Citrus taxonomy was based on mainly morphological and geographical data in the past and many classification systems have been formulated. Two of these systems suggested by Swingle \& Reece (1967) and Tanaka (1977) have been the most widely accepted. The number of recognized species is the major difference between two systems. Swingle recognized 16 species in the genus Citrus, whereas Tanaka (1977) recognized 162 species. Scora (1975) and Barrett \& Rhodes (1976) suggested that there are only three 'basic' true species of Citrus within the subgenus Citrus as follow: citron (C. medica L.), mandarin (C. reticulata Blanco), and pummelo (C. maxima L. Osbeck). Later, Scora (1988) added C. halimi as another true species. Other cultivated species within Citrus were derived from hybridization between these true species or closely related genera followed, mainly, by natural mutations. Recently, this thesis has gained support from various biochemical and molecular studies (Federici et al., 1998; Nicolosi et al., 2000; Barkley et al., 2006; Uzun et al., 2009a). Elucidating relationships, taxonomy, and diversity is important for developing breeding strategies, conserving biodiversity, and improving breeding efficiency. Also understanding genetic variability in citrus is critical for characterizing germplasm, controlling genetic erosion and the registration of new cultivars (Herrero et al., 1996; Barkley et al., 2006).

Use of molecular markers has more advantages than that of morphologically based phenotypic characterization, because molecular markers are generally unaffected by external impact. It is possible to compare accessions of a collection at any time of year using molecular markers, while phenotypic characteristics can be influenced by environmental or cultural affects (The Citrus and Date Crop Germplasm Committee, USA,CDCGC, 2004). Regarding to germplasm management molecular characterization has a number of applications such as relationships between accessions, characterizing newly acquired germplasm, monitoring shifts in population genetic structure in heterogeneous germplasm, exploiting associations among traits of interest and genetic markers and genetic enhancement (Bretting and Widrlechner, 1995, as cited in The Citrus and Date Crop Germplasm Committee, USA, CDCGC, 2004). 
In the present study, we summarized genetic variations and relatioships among citrus species and cultivars mostly cultivated. While preparing this, many studies were overrewieved to better explain citrus diversity. Better understanding genetic relation in citrus offer more opportunities to conservation and evaluation of genetic resources. It is also important for citrus researcher and breeders to arrange their future studies.

\section{A general view of genetic relationships among cultivated citrus species}

It is suggested that the cultivated citrus derived from the three true species, citron, pummelo, and mandarin (Barrett \& Rhodes, 1976). These three species reproduce sexually and if different cultivars within the species are intermated, the progeny are similar to their parents. The other important types (orange, grapefruit, lemon, and lime) are believed to have originated from one or more generations of hybridization between these ancestral genera. Most of the cultivars of orange, grapefruit, and lemon are believed to have originated from nucellar seedlings or budsports. Currently citrus fruits have high level of morphologic variations and various fruit characteristic because of inter and intraspecific interaction (Fig 1). Consequently, the amount of genetic diversity within these groups is relatively low, in spite of there being many named varieties. Conversely, mandarins, pummelos, and citrons have higher levels of genetic diversity since many of the cultivars have arisen through sexual hybridization (The Citrus and Date Crop Germplasm Committee, USA, CDCGC, 2004).

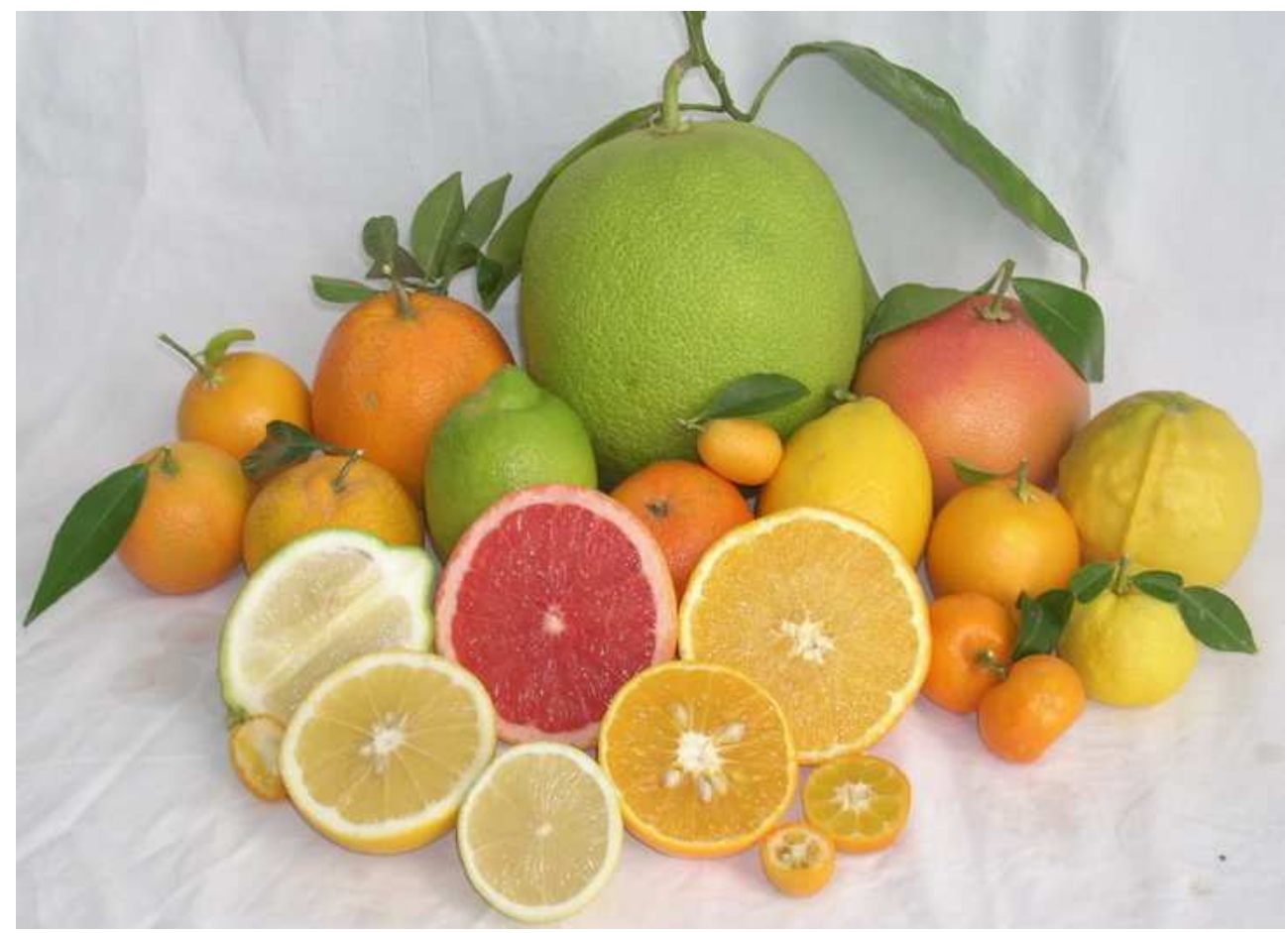

Fig. 1. Citrus fruits have distinct fruit characteristics. 
Relationships among citrus species was invastigated previously. In a recent study, citrus accessions were divided into two large groups. The first group included citron, lemon, lime, rough lemon, with a similarity value of 0.60 from other Citrus species (Uzun et al., 2009a). The similar results were reported in previous studies (Federici et al., 1998; Nicolosi et al., 2000; Barkley et al., 2006). Citron was one of the progenitor of lemons (Nicolosi et al., 2000; Gulsen \& Roose, 2001). It was reported that lemons were thought to be natural hybrids of a citron and a lime (Scora, 1975; Barrett \& Rhodes, 1976) or a hybrid of citron and sour orange (Nicolosi et al., 2000; Gulsen \& Roose, 2001). Limes are apparently hybrids of citrons and papedas (Scora, 1975) or a tri-hybrid cross of citron, pummelo, and Microcitrus, and had the highest observed heterozygosity of all the taxonomic groups (Barrett \& Rhodes, 1976; Nicolosi et al., 2000; Barkley et al., 2006). Rough lemon was reported as hybrid of mandarin and citron (Scora, 1975). C. volkameriana was clustered with rough lemon as in the RAPD and SCAR study, and reported as a hybrid between citron and sour orange (Nicolosi et al., 2000).This finding supports the citron as major progenitor of some commercial citrus cultivars such as all 'true' lemons, limes and rough lemon.

Sweet orange, mandarin, sour orange, pummelo and grapefruit nested in same large group in previous study (Uzun et al., 2009a). This group separated two subgroup at similarity level of 0.64. The first subgroup included sweet oranges, mandarins and sweet oranges were separated from mandarins at 0.78 . Parental sweet orange tree was a hybrid of pummelo and mandarin (Scora, 1975; Barrett \& Rhodes, 1976), which was later supported by Nicolosi et al. (2000). Barkley et al. (2006) suggested that sweet orange has a majority of its genetic makeup from mandarin and only a small proportion from pummelo. The second subcluster included pummelo, grapefruit and sour orange. In this subcluster, pummelos and grapefruits were separated from sour oranges with a similarity value of 0.68 . Pummelos and grapefruits showed a similarity level of 0.83 . Grapefruit was reported as a hybrid of pummelo and sweet orange (Barrett \& Rhodes, 1976; Nicolosi et al., 2000), and all grapefruit cultivars originated from single parent through mutations (Corazza-Nunes et al., 2002). Pummelo was indicated as one of the 'true basic species' in cultivated Citrus (Barrett \& Rhodes, 1976). On the other hand, sour orange was reported as a hybrid of mandarin and pummelo in previous studies (Barrett and Rhodes, 1976; Barkley et al., 2006; Abkenar et al., 2007).

'Rangpur' lime (C. limonia) and bergamot (C. bergamia) were nested in the same branch and closely related to sour orange (Uzun et al., 2009a). Sour orange was reported as a hybrid of mandarin and pummelo in previous studies (Barrett \& Rhodes, 1976; Barkley et al., 2006; Abkenar et al., 2007). Low level of genetic variation was found among sour oranges (Uzun, 2009). On the other hand, there was no polymorphism in sour oranges based on leaf isozymes (Torres et al., 1978) and SSR markers (Luro et al., 2000). Torres et al. (1978) reported that 'Rangpur' lime is quite different morphologically and genotypically from limes and was listed under C. reticulata. Nicolosi et al. (2000) indicated that 'Rangpur' was a hybrid of citron and mandarin and clustered with the citrons. According to Barkley et al. (2006), Webber (1943) believed that rangpurs were more similar to mandarins therefore, the origin and parentage of the rangpurs has been unclear, but they have generally been classified with mandarins in most previous studies. Hodgson (1967) suggested origin of bergamot was obscure, but probably related to sour orange. This accession was identified as a hybrid of citron and sour orange (Nicolosi et al., 2000) and clustered with sour orange (Federici et al., 1998). 


\section{Genetic diversity in orange}

In the cultivated citrus, sweet orange (C. sinensis L. Osbeck) originated as a natural hybrid between mandarin and pummelo (Barrett \& Rhodes, 1976), showed low level of genetic diversity according to lots of previous studies (Luro et al., 1995; Novelli et al., 2000; Novelli et al., 2006; Uzun, 2009). It is notified that most of sweet oranges obtained by mutation from one ancestor tree. So despite of differences in morphological characters, genetic variation of sweet orange was low (Fang \& Roose, 1997).

In recent study carried out using large amount of orange showed that there was high level of genetic similarity in oranges (Uzun, 2009). Similarity level of 250 orange accessions varied between 0.86 and 1.00. 'Chironja' was the most distant cultivar with 0.86 of similarity because of it derived from zygotic origin. This cultivar considered as a hybrid of orange and grapefruit and originated to Puerto Rico. Also it has large fruit and light yellow rind color (Fig. 1) (Hodgson 1967). Ambersweet had zygotic origin also separated clearly from other oranges. It is notified that this cultivar was a hybrid between a genotype obtained 'Orlando' tangelo $\mathrm{X}$ Clementine mandarin and unknown oranges (Jackson \& Futch, 2003). Genetic similarity of all of other oranges was over 0.98 and some of them were identical. In this group there were many common orange cultivars and clones such as, many 'Washington Navel', 'Valencia' , 'Moro', 'Shamouti', 'Pineapple', 'Parson Brown', 'Salustiana', 'Sanguinello', 'Tarocco' and 'Yafa' clones introduced from other countries or selected in Turkey. On the other hand, lots of Turkish orange cultivars and clones for example, 'Agma', 'Alanya Dilimli', 'Dortyol Yerli', 'Kozan Yerli', 'Sultanhisar Yerli', also were existed in that group. Same results also reported in other studies. Barrett \& Rhodes (1976) notified variations in orange, lemon, grapefruit and lime based on mutations occurred on one ancestor tree. Roose (1988), reported it was difficult to distinguish cultivars originated mutations using isozyme markers. Low level of polymorphism in orange also found with ISSR (Fang \& Roose, 1997), SSR (Luro et al., 2000; Novelli et al., 2006), SRAP (Uzun et al., 2009a). On the other hand, no variation found in studied oranges in some researchs (Orford et al., 1995; Qing-Qin et al., 2007).

Orange cultivars are classified into four groups: common, low acidity, pigmented and navel oranges (Hodgson, 1967, as cited in Novelli et al., 2006). It is indicated despite the existence of substantial diversity among cultivated genotypes in respect of morphological, physiological and agronomic traits, very little DNA variation has been detected using DNAmarkers (Novelli et al., 2006). Same researcher found low level of genetic polymorphism among 41 orange cultivars. Similarity level of oranges varied between 0.96 and 1.00 and most of them were identical. They notified that sweet oranges have a narrow genetic basis and that most morphological characters originated through mutations, and clonal propagation of sweet oranges is the case for the majority of citrus species ((Herrero et al., 1996; as cited in Bretó et al., 2001). Fang \& Roose (1997) used ISSR markers to differentiate 41 samples of orange belongs to three groups, Valencia, blood and navel based on fruit traits. All of these cultivars found almost the same ISSR fingerprints. This notified as majority of sweet orange cultivars derived from a single ancestor by mutation. However, some cultivar distinguished from others. Among the seven Valencia orange cultivars, only 'Midknight' differed from the other Valencias. Among the blood oranges, four of the five cultivars showed unique fingerprints for 1-3 fragments which distinguished them from all other sweet orange cultivars. Also 9 of 21 navel oranges had unique fingerprint patterns. Two Parent 'Washington' and 'Navel' samples obtained from different locations differed. It is 
explained as only case in which replicate samples of the same cultivar from different locations had different ISSR fingerprint patterns. It is indicated this result suggests that mutation occurred in at least one of them although horticultural traits are not known to between them (Fang \&Roose, 1997). In other study, it was found identical microsatellite profiles at 9 out of 10 SSR loci among analyzed orange cultivars and clones (Hvarleva et al., 2008). For one locus 'Frost Valencia' and 'Shekeriko' acidless local Cyprus orange were discriminated from 'Shamouti', 'Jaffa', 'Valencia long' and 'Aematousiki' oranges. Researchers also investigated high level of similarity of genotypes, cultivars and clones is in contrast with the observed phenotypic variability among them (Fig. 2), indicating that the local cultivars were possibly derived through mutations which are not detectable by the used SSRs or they are clones of the same original cultivars. This is in accordance with the view that most of the orange cultivars were derived through mutations which affect mostly fruit traits.
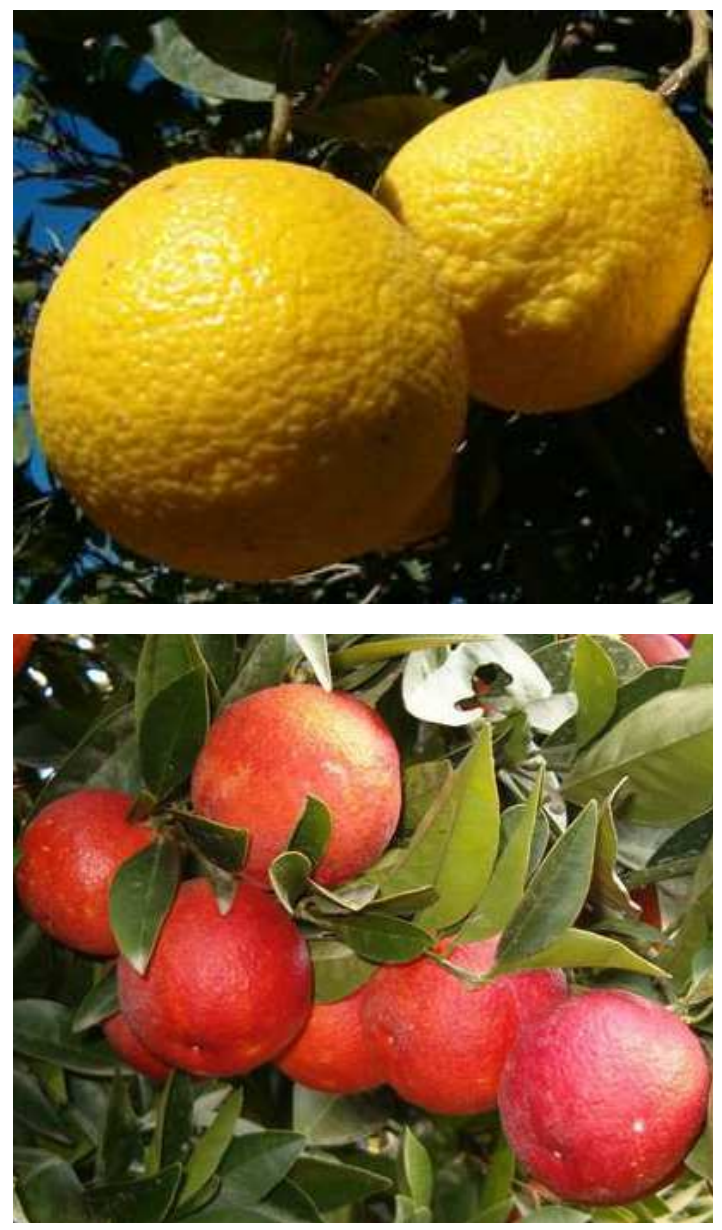

Fig. 2. Fruit image of 'Chironja' (top) and 'Moro' (bottom) orange cultivars showed phenotypic variation among oranges( from Uzun, 2009). 


\section{Genetic diversity in mandarin}

Mandarin was considered as one of the true citrus species (Barrett \& Rhodes, 1976) and this idea supported by following researches (Nicolosi et al., 2000; Barkley et al., 2006; Uzun et al., 2009a). Mandarin group has great amount of cultivars and some of them originated from hybridization and the others derived from mutation. So, in the mandarins obtained from hybrid origin there was clear genetic variation. On the other hand, low level of diversity observed in the cultivars occurred by mutation such as Satsuma and Clementine groups (Breto et al., 2001; Barkley et al., 2006; Uzun et al., 2011a).

In the recent study carried out with SRAP markers, mandarins separated two large groups at similarity level of 0.79 (Uzun, 2009). Satsuma and Clementine mandarins was nested in different groups. 'King' mandarin (Citrus nobilis Loureiro) late maturing and has large fruit cultivar found closely to Satsuma group. It was also reported by Coletto Filho et al. (1998) that genetic similarity among mandarins was over 0.77 and Satsuma and 'King' nested in the same gruop. Nicolosi et al. (2000) found that Satsuma and King closely related according to their RAPD and SCAR data. 'Kara' reported as a hybrid from 'Owari' Satsuma X 'King' (Hodgson, 1967), grouped closely to Satsuma mandarins according to SRAP data (Uzun, 2009). Low level of genetic variation found in most Satsumas and similarity level of nearly 50 accessions was over 0.98 . They separated several group including 2-15 accessions and there was no genetic differences into the each groups. In the another study, there was no variation among the 16 Satsuma mandarin and it was notified these genotypes obtained from mutations. In the same way, Fang and Roose (1997), found no differences in five Satsuma cultivars and Barkley et al. (2006), reported nearly all cultivars in the Satsuma group originated from mutations and they had same genetic construction. Hodgson (1967), classified Satsuma as seperate group in the mandarins and notified that Satsuma naming as Citrus unshiu Markovitch. Also same researcher reported Satsuma was a nonstable group and lots of cultivars and genotypes had been occurred by variations in this group.

In citrus many economically important genotypes are obtained from hybridization. In the mandarin group there are lots of hybrid accessions derived from mandarin $\mathrm{x}$ mandarin, mandarin $\mathrm{x}$ pummelo (as tangelo), mandarin $\mathrm{x}$ orange (as tangor) or mandarin $\mathrm{x}$ tangelo. According to SRAP data, all tangelos and tangors closely related to mandarin instead of orange and pummelo (Uzun, 2009). On the other hand, 'Ellendale', 'Ortanique', 'Mandora', 'Lake' tangelo, 'Orlando' tangelo (Fig. 3.), 'Thornton', tangelo, 'Seminello' tangelo, 'Sampson' tangelo and 'Robinson' and 'Nova' mandarins (both cultivars are result of Clementine $X$ Orlando) grouped closely. 'Ortanique' and 'Mandora' were nearly identical and these cultivars were showed as synonym (Cottin, 2002). On the other hand, 'Ortanique' was reported as a natural hybrid between orange and mandarin (Hodgson, 1967). Also 'Robinson' and 'Nova' shared same parents had the high level of similarity. 'Dancy' mandarin separated clearly from other mandarins and nested alone in the dendrogram obtained by SRAP data (Uzun, 2009). According to Hodgson (1967), this cultivar classified as a species by Tanaka (1954) and originated from India. 'Tankan', 'Ponkan', 'Minneola' tangelo (Fig. 3.), 'Batangas', 'Swatow' nucellar and 'Fuzhu' grouped closely. 'Ponkan' and 'Batangas' were notified as a synonym (Cottin, 2002). Besides, 'Tankan' was reported as hybrid of mandarin and orange (Coletta Filho et al., 1998). Other cultivars have hybrid origin that 'Fremont', 'Kinnow' and 'Murcott' were nested together. 'Fremont' obtained from crossing of 'Clementine' $X$ 'Ponkan' and 'Murcot' known as hybrid of mandarin and orange (Hodgson, 1967). 'Sunburst', 'Fairchild', 'Encore' 
and 'Bower' clustered in same small group (Uzun, 2009). Also 'Sunburst' and 'Fairchild'found as closely related and clustered same group in other study (Barkley et al., 2006). 'Fairchild' was a hybrid of 'Clementine' $X$ 'Orlando' and 'Encore' was a hybrid of 'King' X 'Willowleaf' (Hodgson, 1967). 'Fortune' as a hybrid between 'Clementine' and 'Dancy' (Hodgson, 1967), was found more related to 'Clementine' instead of 'Dancy' (Barkley et al., 2006; Uzun, 2009). 'Lee' as 'Clementine' hybrid clustered closely to 'Clementine' than other 'Clementine' hybrids such as 'Nova' and 'Robinson' (Uzun, 2009).
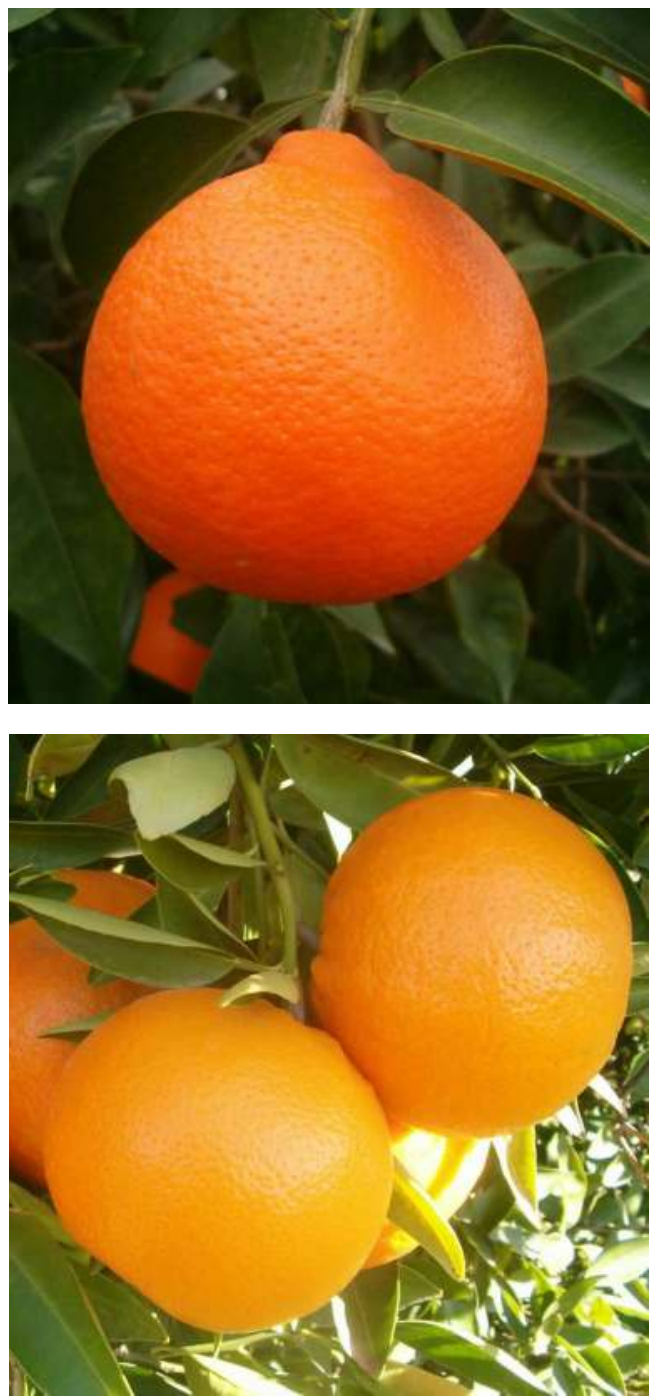

Fig. 3. 'Minneola' (top) and 'Orlando' (bottom) tangelos have same parentage (hybrid of Duncan grapefruit and Dancy mandarin) and contributed to the parentage of the such mandarin. 


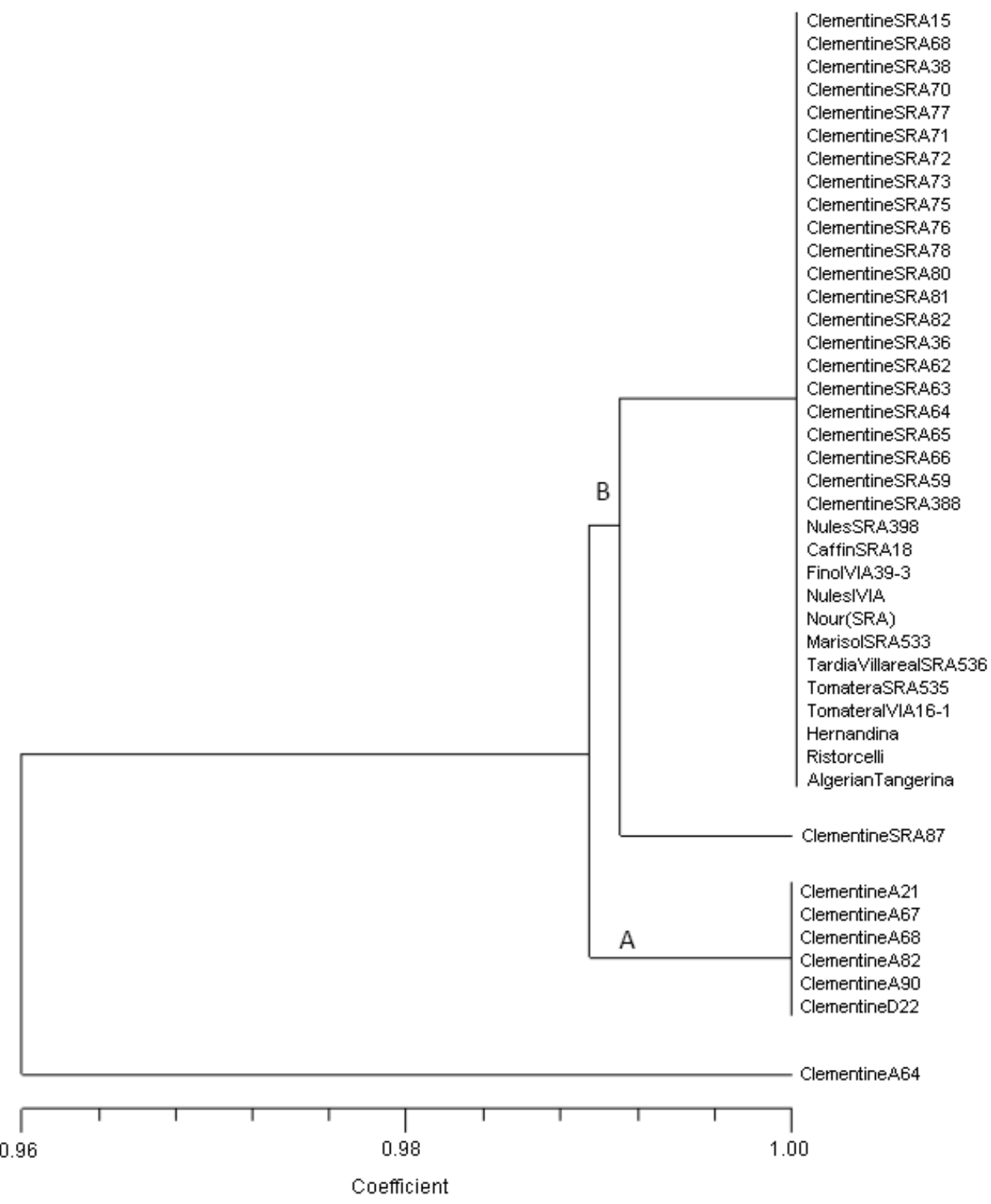

Fig. 4. Dendrogram showed relationships among 42 Clementine accessions based on SRAP markers (from Uzun et al., 2011a).

Clementine (Citrus clementina Hort. ex Tan.) was classified as a Citrus species (Tanaka, 1977). Currently, this species is one of the most important mandarin hybrid especially in the Mediterranean countries due to its good fruit quality and flavour, high yield, easy peeling. A lot of Clementine clones with high quality and different maturity time were obtained from clonal selection and most of them registered as new cultivars. Bud mutations often 
arise in Clementine, as it is the case also for orange and Satsuma mandarin, which are generally detected by the growers in branches of trees showing altered horticultural traits, such as maturity and flowering time, or fruit characteristics (Breto et al., 2001). Contrasting with this diversity for agronomic traits, very low genetic variability has been found in cultivated citrus (Fang \& Roose, 1997; Federici et al., 1998; Coletta-Filho et al., 1998; Luro et al., 2000; Breto et al., 2001; Corazza-Nunes et al., 2002, Uzun et al., 2011a). According to recent study carried out with 42 Clementine accession using SRAP markers genetic similarity of Clementine mandarins over the 0.96 (Uzun et al., 2011a). As a Turkish selection 'Clementine A 64' seperated from other accessions. The rest of 41 accessions divided two groups at 0.99 (A and B). Group A consisted of six Clementine accessions' selected in Turkey and all of them were identical (Fig. 4). Group B included 35 foreign Clementine accessions and 34 of them were identical. Only 'Clementine SRA 87' was distinguished from others in this group.

In a study (Uzun et al., 2011a) genetic diversity of Clementine accessions was very low and most of them were indistinguished. Seven accessions originated in Turkey were separated from foreign accessions. Six of seven Turkish selection were identical. Turkish and other accessions grouped based on their geographic origin whereas accessions originated from other countries such as SRA series from France except 'Clementine SRA 87', 'Fino' from Spain and 'Algerian Tangerina' from Algeria, were indistinguished. It can be explained that Turkish accessions have low level of polymorphism due to long period of cultivation in Turkey without influence of foreign cultivars. It is reported previously that there was limited number of polymorphism in Clementine based on RAPD data and it is suggested Clementines were genetically similar (Russo et al., 2000). Breto et al. (2001), found low level of polymorphism, distinguished only two accessions and notified Clementines are vegetatively propagated and the new cultivars are obtained after careful selection of spontaneous somatic mutations. Luro et al. (2000) speculated that the microsatellites could not distinguish mutation-derived species such as sweet and sour orange, whereas polymorphism was detected among lemon and citron cultivars.

\section{Genetic diversity in lemon and relatives (citron, rough lemon, C. volkameriana)}

Citron that major progenitor of some commercial Citrus cultivars such as all true lemons and rough lemon was reported as one of the "basic" true Citrus species and (Barrett \& Rhodes 1976; Gulsen \& Roose 2001). Lemon (C. limon (L.) Burm. f.) was accepted as a species by two important taxonomic systems (Swingle \& Reece 1967; Tanaka, 1977), but it has been reported as a hybrid by other studies (Barrett \& Rhodes 1976; Torres et al., 1978; Herrero et al., 1996). Besides, lemon was notified as a hybrid of citron and sour orange (C. aurantium L.) in recent studies (Nicolosi et al. 2000; Gulsen \& Roose 2001). Most lemons have highly similar morphological and biochemical characters, and some are reported to have originated by mutation from a single parental lemon tree. Rough lemon (Citrus jambhiri Lush) was reported to be closely related with the citrons in previous studies (Federici et al., 1998; Nicolosi et al., 2000; Barkley et al., 2006; Pang et al., 2007) and was also reported as a hybrid of mandarin and citron (Scora 1975; Nicolosi et al., 2000; Barkley et al., 2006). Citrus volkameriana was reported as a hybrid between citron and sour orange (Nicolosi et al., 2000). 
In a recent study genetic diversity in citron, lemon, rough lemon and C. volkameriana group was carried out using SRAP and SSR markers. They evalutaed 56 accessions were evaluated (Uzun et al., 2011b). Similarity level of citrons to other accessions were $\sim 0.70$. Four citron accessions that 'Buddhas Hand' (fingered citron, Fig. 5) , 'Etrog' and two Turkish selections were distinguished clearly (Fig. 6). Similarly, Gulsen and Roose (2001), reported that similarity level of citron and lemon-rough lemon group was 0.65 based on their ISSR data. On the other hand, according to Uzun et al. (2011b), genetic similarity among lemons and rough lemon-C. volkameriana group was 0.80 . Rough lemons and C. volkameriana were closely related. At the same way, $C$. volkameriana was clustered with rough lemon as in the RAPD (Luro et al., 1992) and SCAR (Nicolosi et al., 2000) based studies.

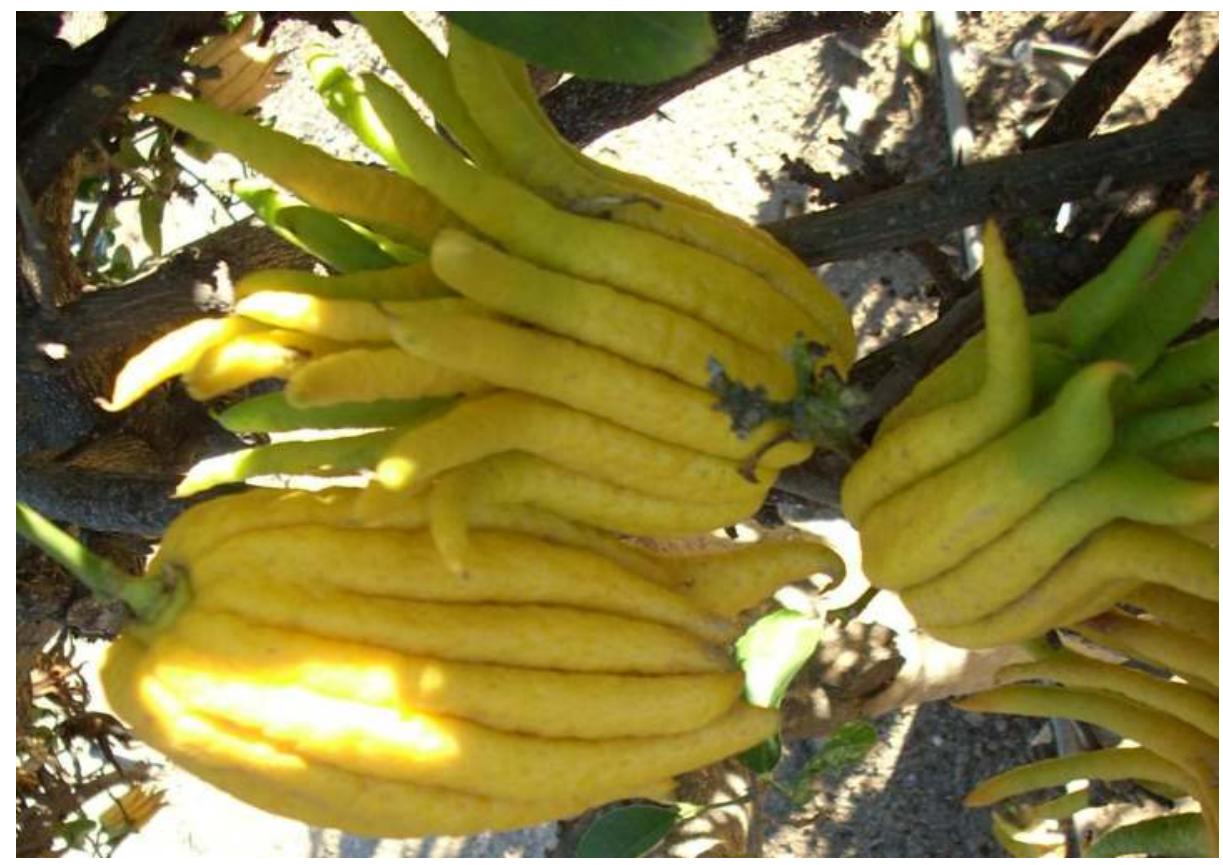

Fig. 5. Fruit shape of 'Buddhas Hand' (fingered citron)

It is reported there was low level of polymorphism among most of lemons derived via clonal selection whereas higher genetic diversity was found in lemons which had hybrid origin (Uzun et al., 2011b). Genetic similarity of 45 lemons included both mutation and hybrid origin was notified between 0.80-1.00 (Fig. 6). The most distinct cultivars were 'Ponderosa' and 'Song Panache'. 'Ponderosa' was suggested as citron like fruits and notified as monoembryonic with large fruits and hybrid of citron and lemon (Hodgson 1967; Kahn et al., 2001). At the same way, 'Ponderosa' was the most distant cultivar from the other lemons based on leaf isozyme data (Torres et al., 1978). On the other hand, 'Song Panache' lemon have similar-shaped fruit as 'Ponderosa'. Another hybrid origin lemon 'Meyer' also separated from other lemons based on SRAP and SSR data (Uzun et al., 2011b). This cultivar was classified as lemon-resembling fruit by Hodgson (1967). Some Turkish lemons had hybrid origin such as 'Tuzcu 09 Aklimon' and its selections 'Tuzcu 896' and 'Tuzcu 897' was 
distinguished. These lemons were also found as distinct from others in previous studies (Aka-Kacar et al., 2005; Uzun et al., 2009b).

Interdonato' lemons was clearly separated from others and genetic similarity among 'Interdonato' lemons was very high caused by their mutation origin (Uzun et al., 2011b). This cultivar was reported as a hybrid between lemon and citron (Hodgson 1967; Gulsen and Roose 2000). "Interdonato" was found as apart from other lemons in previous studies carried out with different marker systems (Deng et al. 1995; Gulsen and Roose 2001).

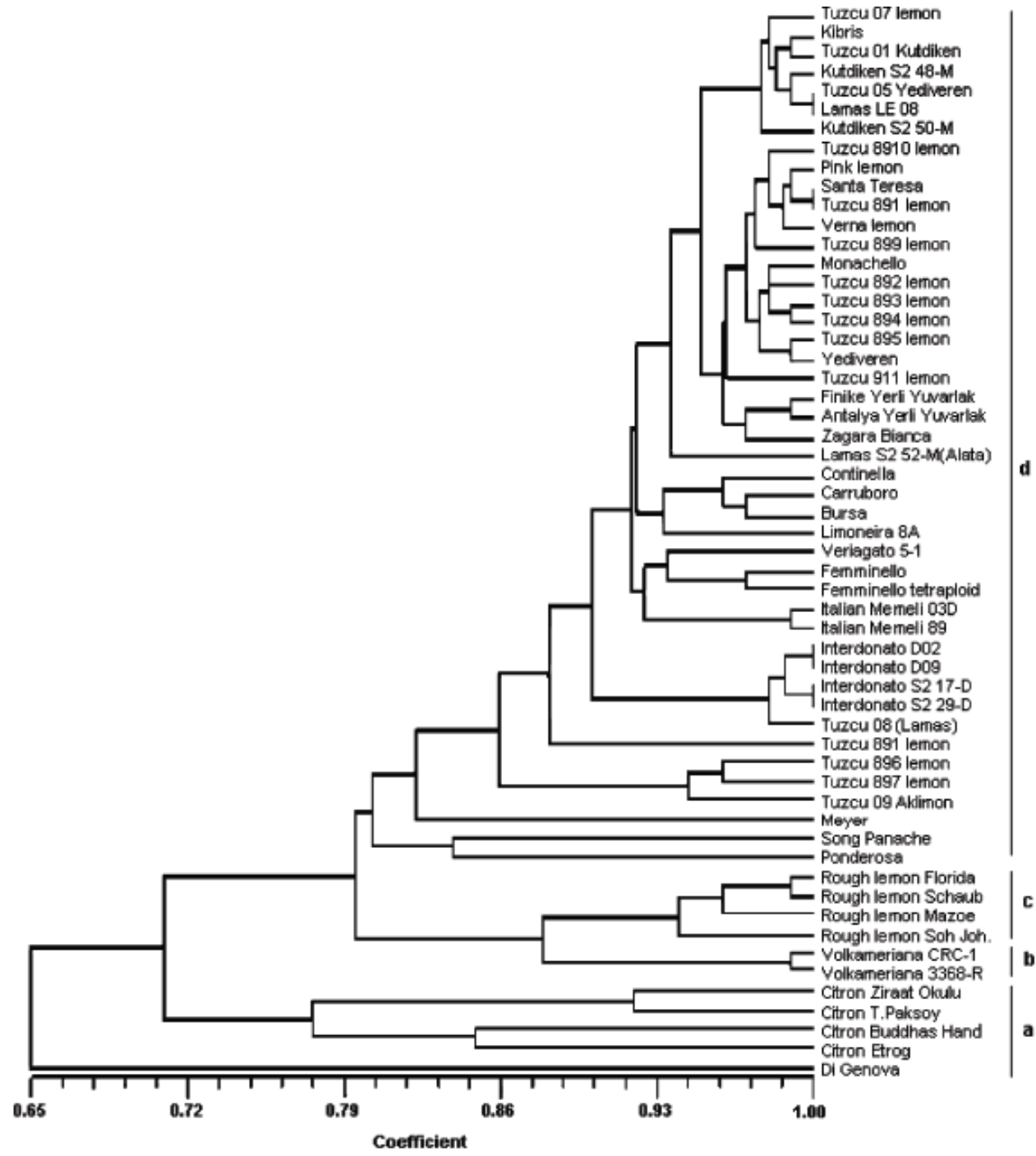

Fig. 6. Dendrogram showed relationships among citron, rough lemon, C. volkameriana and lemons (a; citrons, b: C volkameriana, c: rough lemons, d: lemons; from Uzun et al., 2011b) 
It is notified that although they were distinguished genetic similarity of most of lemon was very high ( 0.92-1.00) (Uzun et al., 2011b). Similar knowledge also was allowed by Gulsen \& Roose (2001) and they indicated most lemons originated from mutation. This group included some lemons from different countries such as 'Femminello', Zagara Bianca', Carruboro', 'Continella', 'Limoneira 8A', 'Santa Teresa', 'Verna', 'Monachello' and several from Turkey that 'Kutdiken', 'Yediveren', Italian Memeli', 'Lamas', 'Kibris'. There was high level of similarities between Turkish and other lemon accessions and there was no clear clustering according to their origin. Although most lemons studied were distinguished, diversity level among these lemons was low (Uzun et al., 2011b).

As an important citrus rootstock sour orange was investigated partly in terms of genetic diversity in some studies. Recently, Lombardo et al. (2011) studied genetic variability of eight sour oranges using ISSR markers. They found a very low level of genetic variability among the cultivars; 'Canaliculata' formed a separated cluster with orange, suggesting a probable hybrid origin derived from crossing between sour and sweet orange. On the other hand, six sour oranges shared the same ISSR fingerprinting pattern not allowing to genetically distinguish anyone of them, while morphologically, they are notably different for the peculiar traits of the fruit and/or leaves. 'Crispifolia' was closely related to the previous six cultivars, suggesting a common origin of the group. Authors notified that this very low or absent genetic variability could be explained on the basis that these particular characteristics depend from mutations that do not varythe DNA length between the simple sequence repeats.

High level of genetic similarity in sour orange also reported by other researchers. Barrett and Rhodes suggested variations in orange, lemon, grapefruit, sour orange and lime based on one ancestor tree. Torres at al. (1978) found any differences in 15 sour oranges accordingto their leaf isozyme data. Luro et al. (2000) found no polymorphism among 10 accession of sour orange with SSR markers. Recently, Uzun (2009) also found very narrow genetic diversity in sour oranges. Besides sour oranges had hybrid origin such as 'Australian' or 'Smooth Seville' were distinguished from other accessions.

\section{Genetic diversity in grapefruit and pummelo}

The grapefruit (C. paradisi Macf.) was notified as a natural hybrid between pummelo (Citrus maxima (Burm.) Merr.) and sweet orange (C. sinensis L. Osb). It originates from Barbados in the Caribbean islands and was first named as Citrus paradisi Macf. by James Macfedyan in 1837 (Scora et al., 1982; Scora, 1988). Grapefruits are highly polyembryonic, therefore they are of nucellar and mutation origin. Genetic variation among common grapefruit cultivars was reported to be very low due to their mutation origin (Fang \& Roose 1997; CorazzaNunes et al., 2002).

The pummelo is native to tropical and subtropical regions in Asia and has been cultivated China for over 2000 years (Corazza-Nunes et al., 2002; Yong et al., 2006). Pummelo was reported as one of the three true citrus species by Barrett and Rhodes (1976) and most of subsequent studies were in agreement with this statement (Federici et al. 1998; Nicolosi et al., 2000; Barkley et al., 2006; Uzun et al., 2009a). Pummelo has played an important role as a parent of many citrus fruits, such as lemons, oranges and grapefruits.

In recent studies genetic variation in pummelo and grapefruit were investigated. Uzun et al., (2010), was determined genetic diversity among 35 accessions of grapefruits and pummelos 
using ISSR markers. In that study, grapefruits and pummelos were seperated clearly and similarity value of this two species was 0.79 . Besides, all pummelos were distinguished and it might be of thier zygotic origin. Same results obtained from SRAP data (Uzun et al., 2011c). At the same way, Yong et al., (2006) also seperated pummelos using SSR markers. It was concluded that pummelos were monoembryonic and there was a high level of polymorphism in the pummelos (Yong et al., 2006).

In the grapefruit group some accessions such as 'Wheeny', 'Citrus hassaku', 'Cocktail' and 'Oroblanco' were clearly separated from pummelos and grapefruits and nested between this two species according to various marker systems (Uzun et al., 2010; Uzun et al., 2011c). 'Wheeny' originated as a chance seedling in Australia and under heat-deficient climatic conditions in Australia and New Zealand it is a summer-maturing variety. While the fruit is grapefruit-like in most respects, the monoembryonic nature of seeds and some ofthe other characters suggest that it is probably a pummelo hybrid (Hodgson 1967). C. hassaku was reported as an independent species (Citrus hassaku Hort. Ex Tanaka) and originated as a chance seedling in Japan and its characteristics strongly suggest the pummelo-mandarin parentage with pummelo predominant (Hodgson 1967). On the other hand, C. hassaku was notified as a pummelo hybrid (Kahn et al., 2001). 'Cocktail' was indicated as a hybrid between 'Frua' mandarin and low acidity pummelo (Kahn et al.,. 2001). Another accession 'Oroblanco' was reported as a hybrid between acidless pummelo and grapefruit (Kahn et al., 2001).

High level of similarity was found in grapefruit cultivars in various studies. Low level of polymorphism was detected in grapefruits and some of them were identical (Uzun et al., 2010; Uzun et al., 2011c). Fang and Roose (1997) found very low polymorphism in grapefruits based on ISSR data and notified that all grapefruits were derived from the same ancestral tree by mutation. There was no variation in grapefruits in other previous studies based on izozyme (Roose, 1988) and SSR (Luro et al., 2000) data. At the same way, Corazza-Nunes et al. (2002) detected high level of similarity in grapefruits. Most grapefruits, despite considerable variation in agronomical traits such as, rind and flesh color, fruit size, were nearly identical (Fig. 7). Cultivars with distinct morphological characters (pigmented or yellow flesh colour, seedy and seedless fruits) such as Henderson, Ruby, Duncan showed complete genetic similarity (Uzun et al., 2010).
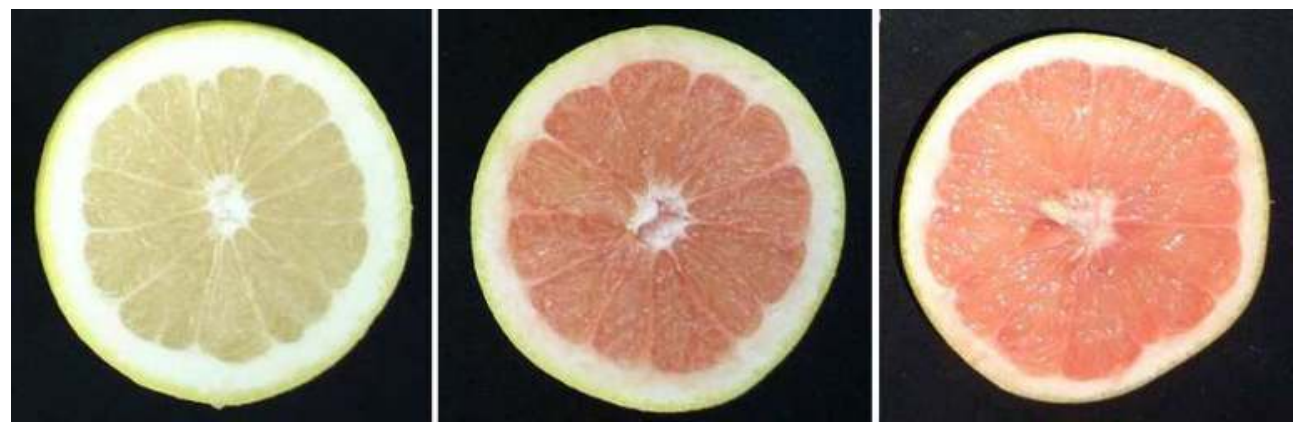

Fig. 7. Although grapefruits have distinct fruit characters, low level of genetic variation found among them (from left to right; Davis Seedless, Shambar, Red Blush). 


\section{Conclusion}

It is reported preservation of the genetic diversity represented in all the plant ecosystems throughout the world has become a major issue of international concern. The loss of increasingly large numbers of plant species through habitat destruction threatens the availability of a diverse plant germplasm base which will be needed to feed future generations. Ex-situ conservation of genetic resources of citrus was considered as imperative for this situation. (Bretting and Widrlechner, 1995, as cited in The Citrus and Date Crop Germplasm Committee, USA, CDCGC, 2004). Approaches to ex-situ conservation include methods like seed storage, field genebanks and botanical gardens. DNA and pollen storage also contribute indirectly to ex-situ conservation of genetic resorces. Advances in biotechnology, especially in the area of in vitro culture techniques and molecular biology provide some important tools for improved conservation and management of plant genetic resources (Rao, 2004).

It is suggested better understanding of genetic diversity and its distribution is essential for its conservation and use. It will help us in determining what to conserve as well as where to conserve, and will improve our understanding of the taxonomy and origin and evolution of plant species of interest. Information of these subjects is essential for collecting and use of any plant species and its wild relatives. Understanding genetic diversity that is present in collections is required to better management of conserved germplasm. Through improved characterization and development of core collections based on genetic diversity information, it will be possible to exploit the available resources in more valuable ways (Rao \& Hodgkin, 2002).

Genetic variability in citrus is considered to be the result of many factors, such as hybridization, mutation and type of reproduction (mostly apomictic). The low intraspecific diversity found in cultivated species such as sweet orange contrasts with the high variability of agriculturally important traits such as ripening period and color and size of fruits (Herrero et al., 1996, as cited in Novelli et al., 2006). Understanding of genetic diversity in Citrus is essential for planning and application of breeding programs, establishing germplasm collection and carrying out molecular studies. It is also important for citrus researcher and breeders to arrange their future studies.

\section{Acknowledgements}

The authors wish to thank Kahraman GURCAN from Agricultural Biotechnology Department of Erciyes University for his valuable assistance.

\section{References}

Abkenar, A.A.; Isshiki, S. \&Matsumoto, R. (2007). Comparative analysis of organelle DNAs acid citrus grown in Japan using PCR-RFLP method. Genet. Res. Crop. Evol. 55: 487492.

Barkley, N.A.; Roose, M.L.; Krueger, R.R. \& Federici, C.T. (2006). Assessing genetic diversity and population structure in a citrus germplasm collection utilizing simple sequence repeat markers (SSRs). Theor. Appl. Genet. 112, 1519-1531. 
Barrett, H.C. \& Rhodes, A.M. (1976). A numerical taxonomic study of affinity relationships in cultivated Citrus and its close relatives. Syst. Bot. 1: 105-136.

Breto, M.P.; Ruiz, C.; Pina, J.A. \& Asins, M.J. (2001). The diversification of Citrus clementina Hort. Ex Tan., a vegetatively propagated crop species. Mol. Phylo. Evol.21:285-293.

Coletta-Filho, H.D.; Machado, M.A.; Targon, M.L.P.N.; Moreita, M.C.P.Q.D.G. \&Pompea Jr., J. (1998). Analysis of the genetic diversity among mandarins (Citrus spp.) using RAPD markers. Euphytica 102: 133-139.

Corazza-Nunes, M.J.; Machado, M.A.; Nunes, W.M.C.; Cristofani, M. \&Targon,M.L.P.N. (2002). Assessment of genetic variability in grapefruits (Citrus paradisi Macf.) and pummelos (C. maxima Burm. Merr.) using RAPD and SSR markers. Euphytica 126: 169-176.

Cottin, R. (2002) Citrus of the World, A Citrus Directory Version 2. SRA INRA-CIRAD, France

Deng Z.N.; Gentile, A.; Domina, F.; Nicolosi, E. \&Tribulato, E. (1995) Selecting lemon protoplasts for insensitivity to Phoma tracheiphila toxin and regenerating tolerant plants. J. Am. Soc. Hortic. Sci. 120:902-905

FAO. (2009). Food and Agricultural Organization of the United Nations, http:/ / faostat.fao.org

Fang, D.Q. \& Roose, M.L. (1997). Identification of closely related Citrus cultivars with intersimple sequence repeat markers. Theor. Appl. Genet. 95: 408-417.

Federici, C.T.; Fang, D.Q.; Scora, R.W. \& Roose, M.L. (1998). Phylogenetic relationships within the genus Citrus (Rutaceae) and related genera as revealed by RFLP and RAPD analysis. Theor. Appl. Genet. 96: 812-822.

Gulsen, O.\& Roose, M.L. (2000). The origin of Interdonato lemon inferred from cpRFLP, SSR, isozyme and ISSR markers. Proc. Int. Soc. Citricult. IX Congr. pp. 158-159.

Gulsen, O. \& Roose, M.L. (2001). Lemons: diversity and relationships with selected citrus genotypes as measured with nuclear genome markers. J. Am. Soc. Hort. Sci. 126: 309-317.

Herrero, R.; Asins, M.J.; Carbonell, A.E. \& Navarro, L. (1996). Genetic diversity in the orange subfamily Aurantioideae. I. Intraspecies and intragenus genetic variability. Theor. Appl. Genet. 92: 599-609.

Hodgson, R.W. (1967). Horticultural varieties of citrus. In: Reuther, W., Webber, H.J., Batchelor, L.D. (Eds.), The Citrus Industry, vol. 1. University of California Press, Berkeley, pp. 431-591.

Hvarleva, T.; Kapari-Isaia, T.; Papayiannis, L.; Atanassov, A.; Hadjinicoli, A. \& Kyriakou, A. (2008). Characterization of citrus cultivars and clones in Cyprus through microsatellite and RAPD analysis. Biotechnol. \& Biotechnol. Eq. 22: 787-794.

Jackson, L.K. \& Futch, S.H. (2003). Ambersweet Orange. Fact Sheet HS-176, Horticultural Sciences Department, Florida Cooperative Extension Service, Institute of Food and Agricultural Sciences, University of Florida.

Kahn T.L.; Krueger, R.R.; Gumpf, D.J.; Roose M.L.; Arpaia, M.L.; Batkin, T.A.; Bash, J.A.; Bier, O.J.; Clegg, M.T.; Cockerham, S.T.; et al (2001). Citrus genetic resources in California: Analysis and recommendations for long-term conservation. Report No. 22. University of California Division of Agriculture and Natural Resources, Genetic Resources Conservation Program, Davis, CA, USA. 
Luro F.; Laigret, F.; Bove, J.M. \& Ollitrault, P. (1992). Application of random amplified polymorphic DNA (RAPD) to Citrus genetic and taxonomy. Proc. Int. Soc. Citriculture pp: 225-228

Luro, F.; Laigrent, F.; Bove, J.M. \& Ollitrault, P. (1995). DNA amplified fingerprinting, a useful tool for determination of genetic origin and diversity analysis in Citrus. HortScience 30: 1063-1067.

Luro, F.; Rist, D. \& Ollitrault, P. (2000). Sequence tagged microsatellites polymorphism: an alternative tool for cultivar identification and evaluation of genetic relationships in Citrus. Proc. Int. Soc. Citricult. IX. Congr. Florida, USA. pp: 170-171.

Nicolosi, E.; Deng, Z.N.; Gentile, A.; La Malfa, S.; Continella, G. \& Tribulato, E. (2000). Citrus phylogeny and genetic origin of important species as investigated by molecular markers. Theor. Appl. Genet. 100: 1155-1166.

Novelli, V.M.; Machado, M.A. \& Lopes, C.R. (2000). Isoenzymatic polymorphismin Citrus spp. and Poncirus trifoliata (L.)) Raf. (Rutaceae). Genet. Mol. Biol. 23: 1163-1168.

Novelli, V. M.; Cristofani, M.; Souza, A. A. \& Machado, M. A. (2006). Development and characterization of polymorphic microsatellite markers for the sweet orange (Citrus sinensis L. Osbeck). Genetics and Molecular Biology. 29: 90-96.

Orford S.J.; Steele Scott, N. \&Timmis, J.N. (1995). A hypervariable middle repetitive DNA sequence from citrus. Theor. Appl. Genet. 91:1248- 52.

Pang, X.M.; Hu, C.G. \& Deng, X.X. (2007). Phylogenetic relationship within Citrus and related genera as inferred fromAFLPmarkers. Genet. Res. Crop. Evol. 54: 429-436.

Qing-Qin, C.; Hai-Jun, M.; Xiao-Peng, W.; Hua-Lin, Y. \& Xiu-Xin, D. (2007). Genetic diversity of male sterile and low fertility germplasm of Citrus revealed using SSR markers. Chinese Journal of Agricultural Biotechnology 4: 99-104.

Rao, V.R. \& Hodgkin, T. (2002). Genetic diversity and conservation and utilization of plant genetic resources. Plant Cell, Tissue and Organ Culture, 68: 1-19.

Rao, N.K. (2004). Plant genetic resources: Advancing conservation and use through biotechnology. African Journal of Biotechnology, 3: 136-145.

Roose M.L. (1988). Isozymes and DNA restriction fragment length polymorphisms in Citrus breeding and systematics. Proc. Int. Soc. Citricult. VI. Congr. Margraf Scientific Books, Weikersheim, pp:155-165.

Russo, G.; Corona, M.G. \& Vendramin, G.G. (2000). Identification of Clementine cultivarsecotypes using molecular markers. Proc. Int. Soc. Citricult. IX. Congr. Florida, USA. pp:196-197.

Scora, R.W. (1975). On the history and origin of Citrus. Bull. Torr. Bot. Club. 102: 369-375.

Scora, R.W.; Kumamoto, J.; Soost, R.K. \& Nauer, E.M. (1982). Contribution to the origin of the Grapefruit, Citrus paradisi (Rutaceae). Syst. Bot. 7:170-177.

Scora, R.W. (1988). Biochemistry, taxonomy and evolution of modern cultivated Citrus. Proc. Int. Soc. Citricult. VI. Congr. vol. 1. Margraf Publishers, Weikersheim, Germany, pp. 277-289.

Swingle, W.T. \& Reece, P.C. (1967). The botany of citrus and its wild relatives. In: Reuther, W., Webber, H.J., Batchelor, L.D. (Eds.), The Citrus Industry, vol. 1.University of California Press, Berkeley, CA, USA, pp. 389-390.

Tanaka, T. (1954). Species problems in citrus. Japanese Society for the Promotion of Science, Ueno, Tokyo, $152 \mathrm{pp}$.

Tanaka, T. (1977). Fundamental discussion of Citrus classification. Stud. Citrol. 14: 1-6. 
The Citrus and Date Crop Germplasm Committee, USA (CDCGC). (2004). Citrus and Date Germplasm: Crop Vulnerability, Germplasm Activities, Germplasm Needs. Citrus and Date Crop Germplasm Committee, USA. pp. 1-30.

Torres, A.M.; Soost, R.K. \& Diedenhofen, U. (1978). Leaf isosymes as genetic markers in Citrus. Am. J. Bot. 65: 869-881.

Ulubelde, M. (1985). Turunçgillerin taksonomisi. Ege Bölgesi Zirai Arastırma Enstitüsü Yayınları No:55, p: 43 (in Turkish).

Uzun, A. (2009). Turunçgillerde genetik çeşitliliğin SRAP markırları ile karakterizasyonu (Characterization of genetic diversity of Citrus by SRAP markers) Ph.D. Thesis. University of Cukurova, Institute of Natural and Applied Sciencies. p. 369. (in Turkish)

Uzun, A.; Yesiloglu, T.; Aka-Kacar, Y.; Tuzcu, O. \& Gulsen, O. (2009a). Genetic diversity and relationships within Citrus and related genera based on sequence related amplified polymorphism markers (SRAPs). Scientia Horticulturae, 121:306-312.

Uzun, A.; Gulsen, O.; Kafa, G.; Seday, U.; Tuzcu, O. \& Yesiloglu, T. (2009b). Characterization for yield, fruit quality, and molecular profiles of lemon genotypes tolerant to 'mal secco' disease. Scientia Horticulturae, 122: 556-561.

Uzun, A.; Gulsen, O.; Yesiloglu, T.; Aka-Kacar, Y. \& Tuzcu, O. (2010). Distinguishing grapefruit and pummelo accessions using ISSR markers. Czech J. Genet. Plant Breed. 46: 170-177.

Uzun, A.; Yesiloglu, T.; Aka-Kacar, Y.; Tuzcu, O.; Gulsen, O.; Seday, U. \& Canan, I. (2011a). Genetic diversity and relationships of Clementine mandarin accessions as assessed using SRAP markers. Acta Hort. 892: 65-72.

Uzun, A.; Yesiloglu, T.; Polat, I.; Aka-Kacar, Y.; Gulsen, O.; Yildirim, B.; Tuzcu, O.; Tepe, S.; Canan, I. \& Anil, S. (2011b). Evaluation of genetic diversity in lemons and some of their relatives based on SRAP and SSR markers. Plant Mol. Biol. Rep. 29: 693-701.

Uzun, A.; Yesiloglu, T.; Aka-Kacar, Y.; Tuzcu, O.; Gulsen, O.; Kafa, G.; Yildirim, B. \& Anil, S. (2011c). Genetic diversity of grapefruit and pummelo accessions based on SRAP markers. Acta Hort. 892: 49-56.

Yong, L.; De-Chun, L.; Bo, W. \& Zhong-Hai, S. (2006). Genetic diversity of pummelo (Citrus grandis Osbeck) and its relatives based on simple sequence repeat markers. Chinese J. of Agr. Biotechnology, 3:119-126.

Webber, H.J. (1943). Cultivated varieties of citrus. In: Webber HJ, Batchelor LD (eds) The Citrus Industry, vol 1. University of California Press, Berkeley. pp: 475-668.

Webber, H.J. 1967. History and development of the Citrus industry. In: Reuther, W., Webber, H.J., Batchelor, L.D. (Eds.), The Citrus Industry, vol. 1. University of California Press, Berkeley, pp. 1-39. 


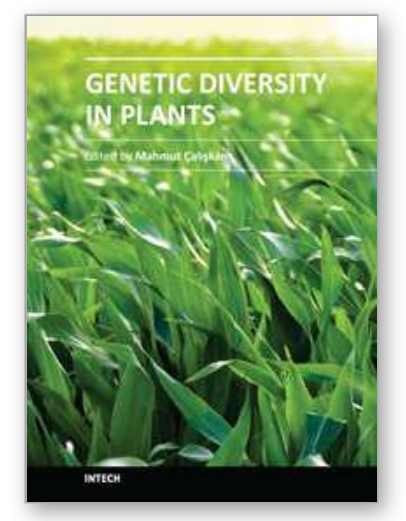

\author{
Genetic Diversity in Plants \\ Edited by Prof. Mahmut Caliskan
}

ISBN 978-953-51-0185-7

Hard cover, 498 pages

Publisher InTech

Published online 14, March, 2012

Published in print edition March, 2012

Genetic diversity is of fundamental importance in the continuity of a species as it provides the necessary adaptation to the prevailing biotic and abiotic environmental conditions, and enables change in the genetic composition to cope with changes in the environment. Genetic Diversity in Plants presents chapters revealing the magnitude of genetic variation existing in plant populations. The increasing availability of PCR-based molecular markers allows the detailed analyses and evaluation of genetic diversity in plants and also, the detection of genes influencing economically important traits. The purpose of the book is to provide a glimpse into the dynamic process of genetic variation by presenting the thoughts of scientists who are engaged in the generation of new ideas and techniques employed for the assessment of genetic diversity, often from very different perspectives. The book should prove useful to students, researchers, and experts in the area of conservation biology, genetic diversity, and molecular biology.

\title{
How to reference
}

In order to correctly reference this scholarly work, feel free to copy and paste the following:

Aydin Uzun and Turgut Yesiloglu (2012). Genetic Diversity in Citrus, Genetic Diversity in Plants, Prof. Mahmut Caliskan (Ed.), ISBN: 978-953-51-0185-7, InTech, Available from: http://www.intechopen.com/books/geneticdiversity-in-plants/genetic-diversity-in-citrus

\section{INTECH}

open science | open minds

\author{
InTech Europe \\ University Campus STeP Ri \\ Slavka Krautzeka 83/A \\ 51000 Rijeka, Croatia \\ Phone: +385 (51) 770447 \\ Fax: +385 (51) 686166 \\ www.intechopen.com
}

\author{
InTech China \\ Unit 405, Office Block, Hotel Equatorial Shanghai \\ No.65, Yan An Road (West), Shanghai, 200040, China \\ 中国上海市延安西路65号上海国际贵都大饭店办公楼 405 单元 \\ Phone: +86-21-62489820 \\ Fax: $+86-21-62489821$
}


(C) 2012 The Author(s). Licensee IntechOpen. This is an open access article distributed under the terms of the Creative Commons Attribution 3.0 License, which permits unrestricted use, distribution, and reproduction in any medium, provided the original work is properly cited. 